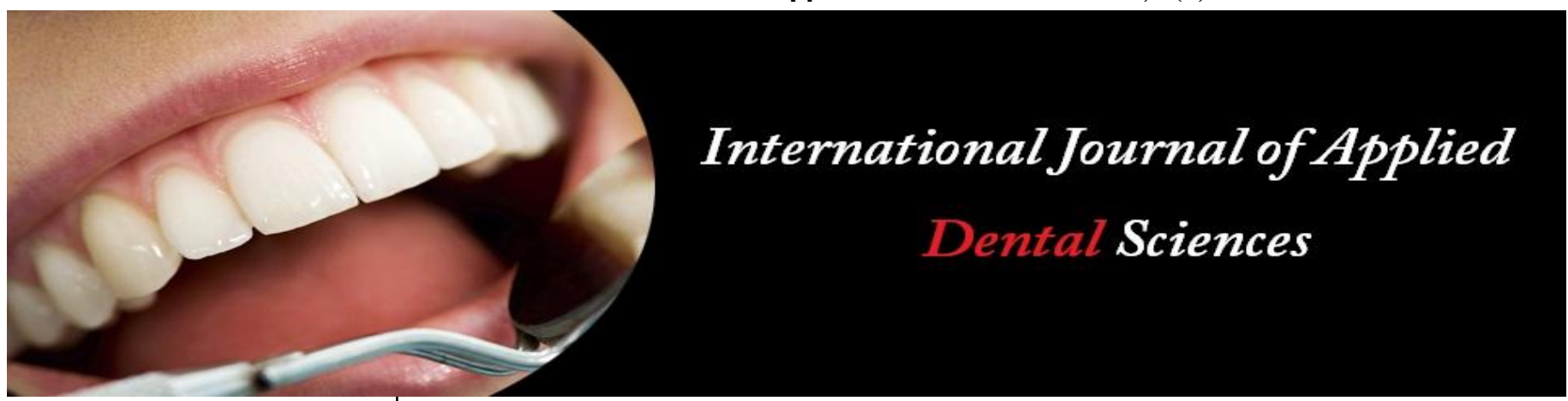

ISSN Print: 2394-7489

ISSN Online: 2394-7497

IJADS 2017; 3(3): 193-199

(C) 2017 IJADS

www.oraljournal.com

Received: 18-05-2017

Accepted: 19-06-2017

Dr. Githanjali Manchikalapudi

Reader, Department of

Prosthodontics, Army College of

Dental Sciences, Secunderabad,

Telangana, India

Dr. Giridhar Kamath

Head of Department of

Prosthodontics, Principal,

Sharavathi Dental

College and Hospital, Shimoga,

Karnataka, India
Correspondence

Dr. Githanjali Manchikalapudi

Reader, Department of

Prosthodontics, Army College of

Dental Sciences, Secunderabad,

Telangana, India

\section{Comparison of the dual-arch impression technique and the complete-arch custom tray impression technique, in the dimensional accuracy of gypsum dies generated, and in patient comfort: A clinical study}

\author{
Dr. Githanjali Manchikalapudi and Dr. Giridhar Kamath
}

DOI: https://doi.org/10.22271/oral.2017.v3.i3c.31

\begin{abstract}
Dual-arch impression trays are often used in fixed Prosthodontics, to generate impressions of the prepared teeth and opposing arch, simultaneously. Lack of support and confinement of the impression material, variation in impression material thickness and flexibility of dual arch impression trays is of concern in generating accurate working dies. A clinical study was conducted to compare accuracy of gypsum dies generated from metal and plastic dual-arch tray impressions with those generated from complete-arch custom tray impressions, using different vinyl polysiloxane impression materials. The level of patient perceived comfort was also assessed. It was concluded that dual arch impressions were preferred by the patients and those made with rigid tray material, produced working dies that were closest to the implant abutment used.
\end{abstract}

Keywords: Dental impression, dental impression technique, vinyl polysiloxane, tray

\section{Introduction}

Dual arch impression technique is a closed mouth impression technique, where a single, double-sided impression is made, to simultaneously imprint the prepared tooth, its adjacent teeth and the opposing tooth segment, in their normal physiological position of maximum intercuspation ${ }^{[1]}$. It is indicated for single posterior indirect restorations ${ }^{[2]}$ and short span fixed partial dentures ${ }^{[3]}$. where a stable maximal intercuspal position and mutually protected occlusion exist.

The major advantage of this technique is reduction in errors and need for occlusal adjustment [4]. The articulated casts have superior accuracy when compared to conventional full arch casts, mounted with either hand articulation or with centric relation records. ${ }^{[5,6,7]}$ This technique minimizes the effects of clinical variables like mandibular flexion on wide opening of mouth and tooth intrusion during maximum intercuspation ${ }^{[1,2]}$. Other proposed advantages are saving in time and material ${ }^{[8,9]}$, patient comfort ${ }^{[1,9,10]}$, ease of use and simultaneous record of prepared tooth, opposing teeth and interocclusal relation.

However, the lack of rigidity in a dual arch tray may lead to flexure of the tray-impression complex, and the resulting rebound could give inaccurate die dimensions and ill-fitting restorations ${ }^{[1]}$. A rigid impression material that can compensate for this flexibility can be used with these trays. Open-mouth complete-arch custom-tray impressions, on the other hand, may produce the most accurate dies ${ }^{[11]}$, but the clinical variables may result in a cast with different maximal intercuspal position and occlusal contacts, to those seen in the patient. ${ }^{[2,12]}$ As such the conventional complete-arch method may result in hyper occlusion ${ }^{[13]}$, while the dual arch method may produce poorly fitting restorations ${ }^{[14]}$.

The dual arch impression technique is widely used clinically; however, the accuracy of dies generated from it remains in question. When fabricating an indirect restoration, distortion inherent in each step of the procedure is additive. Consequently, the choice of the impression technique may be one of the factors that affect the fit of the final restoration. The purpose of this clinical study is to compare the accuracy of dies generated from metal and plastic dualarch tray impressions to those from complete-arch custom trays, using two different vinyl 
polysiloxane tray-impression materials and also to assess the patient perceived comfort with the dual-arch and complete arch custom tray techniques.

\section{Materials and methods}

Fifteen subjects complying with inclusion and exclusion criteria were selected after patient screening, for a comparative clinical study. Informed consent of the subjects was obtained.

Patients with no temporomandibular disorders, requiring prosthetic restoration of a single asymptomatic implant in the molar or second premolar region of either the maxillary or mandibular arch and with reproducible maximum intercuspal position were included in the study. Also, the implant in these patients was bound by teeth on mesial and distal aspect. Patients with removable partial or complete dentures, multiple missing teeth on contralateral quadrants that had not been replaced with fixed restoration and with exaggerated gag reflex were excluded from the study.

The abutment of endosteal implant (Frialit II, Friadent), in each of the 15 subjects was used in make impressions and necessary measurements.

\subsection{Measuring the implant abutment}

The implant abutment, before being engaged to osseointegrated implant in the patient's mouth, was measured in three dimensions of clinical interest, buccolingual, mesiodistal and occlusogingival, using a measuring microscope (Matsuzawa Co. Ltd. Japan.) with an inbuilt camera (Camera Clemex L 1.3M) and a software program (Clemex CMT). Buccolingual and mesiodistal measurements were obtained by measuring the distance between the buccal and lingual grooves, and mesial and distal grooves respectively, at the occlusoaxial portion of the abutment. The point angle on the groove is used, so as to have a reproducible reference point. The position of the abutment during measurement of each dimension is marked for reproduction during the measurement of gypsum working dies. The occlusogingival dimension was obtained by measuring the distance between the occlusoaxial line angle and the gingival finish line of the abutment, along the line angle of the mesial groove. The mean values of measurement of each implant abutment, in 3 dimensions, acted as control when comparing the measurements of gypsum working dies, generated from 6 impressions on each subject.

\subsection{Making definitive impressions of implant abutment}

The measured implant abutment of each subject was sterilized, screwed into position on the implant, and air dried for 5 seconds with air-water syringe. Six definitive impressions of the abutment were made on each subject using 3 different types of trays [Conventional complete-arch custom tray, Dual-arch metal tray (Bite Tray, Essago SBC), Dualarch plastic tray(Capri, posterior bite registration trays, Caprisons, Mumbai)] in combination with 2 different types of heavy body vinyl polysiloxane impression material (Take1 Tray- auto mix cartridges, and Take 1 Rigid Tray- auto mix cartridges, Kerr U.S.A. Romulus, MI), and light body syringe impression material(Take1 Syringe - auto mix cartridges, Kerr U.S.A. Romulus, MI)

One coat of adhesive (Caulk Tray adhesive, Dentsply International Inc, Delaware) was applied to the internal surface and borders of all trays. The complete-arch custom trays were fabricated in auto polymerizing resin with a uniform thickness of $2 \mathrm{~mm}$, wax relief of $3 \mathrm{~mm}$ and four vertical stops on terminal molars and first premolars. The seating of the tray and patient comfort were assessed and borders visually inspected to ensure approximately $2 \mathrm{~mm}$ of clearance from the vestibule. The dual-arch tray was similarly assessed to ensure passive fit, non-impingement on anatomic structures, and ability of patient to close into a rehearsed maximum intercuspal position. ${ }^{[15]}$

The amount of impression material used during each impression was standardized $(1.2 \mathrm{ml}$ syringe material and 11 $\mathrm{ml}$ of tray material) by keeping constant, the number of activations of auto mix cartridges.

During impression making complete-arch tray was seated until the vertical stops were engaged and dual-arch tray was placed onto the implant abutment and patient instructed to close until the contra lateral teeth were in rehearsed maximal intercuspal position. Impression was allowed to set for 5 minutes and removed from the mouth in a single movement to minimize distortion. Impressions with voids and "show through" indicating impingement of anatomic structures, were discarded and remade after corrective measures. Thin and translucent occlusal surfaces of dual arch impressions indicated proper closure into maximum intercuspation. The sequence of the 6 impressions taken in each subject was randomized.

As the patient perceived comfort level of the impression technique was also investigated, each subject was asked to rank the impressions on a scale of 1 to 6,1 being the most comfortable and 6 being the least comfortable. The criterion, used to evaluate comfort, was the subjects' perception of which technique, over all, was the easiest to endure.

\subsection{Pouring the cast and die fabrication}

Impressions were disinfected and poured 60 minutes later in Type IV gypsum (Kalrock; Kalabhai Karson Pvt.Ltd.) following hand mixing for 5 seconds, vacuum mixing (Multivac 4; Degussa, Germany) for 30 seconds and vibration. For dual-arch trays, opposing impression was first poured with dental stone and allowed to set for 1 hour before the abutment side impression was poured. The casts were removed after 24 hours and sectioned to produce gypsum dies.

A code was assigned to the gypsum die obtained from each of six impressions made on every subject ie. CT for completearch tray with Take1 Tray material, CRT for complete-arch tray with Take1 Rigid Tray material, DAPT for Dual-arch plastic tray with Take1 Tray material, DAPRT for Dual-arch plastic tray with Take1 Rigid Tray material, DAMT for Dualarch metal tray with Take1 Tray material and DAMRT for Dual-arch metal tray with Take1 Rigid Tray material. The coded gypsum dies were measured in three dimensions (buccolingual, mesiodistal and occlusogingival) in a procedure similar to that described for the implant abutment.

\section{Statistical analysis}

The dimensional difference of the gypsum die from the implant abutment, in buccolingual, mesiodistal and occlusogingival dimensions was calculated and tabulated. The data obtained was statistically analyzed. To test for significant main effects for the impression type, the data was analyzed with multivariate repeated measures analysis of variance (Oneway ANOVA) with all hypotheses testing conducted at $\alpha$ $=0.05$. A pairwise comparision of the mean values was conducted with Tukey's test.

The comfort level scores assigned by the subjects to each impression type on a scale of 1-6, one being the most comfortable and 6 the least, were analyzed with KrusckalWallis and Mann-Whitney tests. 


\section{Results and Discussion}

Table 1 displays the mean buccolingual measurements of the implant abutments $(3.399 \mathrm{~mm} \pm 0.345 \mathrm{~mm})$ and the mean buccolingual measurements of the gypsum dies obtained from the 6 impression types. The standard deviation associated with the gypsum dies ranged between 0.343 and $0.345 \mathrm{~mm}$ ). All the 6 impression types show a positive mean buccolingual dimensional difference, indicating that the working dies were larger than the corresponding implant abutment in the buccolingual dimension. The larger buccolingual dimension of the gypsum die could be attributed to the tray adhesive used with all the impression trays. During polymerization reaction, the impression material shrinks towards the center of the mass. The use of tray adhesive, however, would redirect this shrinkage towards the impression tray walls, resulting in larger dies in the diameter, bucco-lingually ${ }^{[10,16]}$. Because of the absence of adhesive interproximally, the mesiodistal diameter narrowed down, unrestrained, as the material stretched buccolingually, explaining the smaller mesiodistal dimension of the gypsum die. These results conform to the study conducted by Ceyhan et al. ${ }^{[10]}$ and they followed a similar protocol in terms of tray adhesive and sequence of pour of the casts, but used a monophase material for complete arch custom tray and rigid tray impression material for Dualarch plastic and metal trays. Breeding and Dixon ${ }^{[17]}$ obtained larger dies with plastic dual-arch trays in the buccolingual dimension, even without the use of a tray adhesive. However they obtained smaller dies from metal dual arch trays. One possible explanation for increased dimensions seen with plastic dual-arch trays, in their study, may be distortion caused by the weight of the stone when impression is poured only on the working side. The opposing side was never poured. As metal dual-arch trays would resist any flexure, polymerization shrinkage of impression material towards the center of the mass in absence of a tray adhesive, produced dies that were smaller in dimension. This may also explain the protocol of Wilson and Werrin ${ }^{[3]}$ of "always pouring the counter-impression before pouring the working side impression". This protocol was followed in the present study. The least mean dimensional difference of $0.0062 \mathrm{~mm}$ shown by DAPT and $0.008 \mathrm{~mm}$ by DAPRT indicate that these two impression types produced dies that were closest to the implant abutment in buccolingual dimension and the results were very highly significant $(\mathrm{p}=0.001)$.

Table 2 displays the result of posthoc (Tukey's) for buccolingual dimension. The mean difference is highly significant between the groups DAPT and CT $(\mathrm{p}=0.006)$, DAPT and DAMT $(p=0.005)$. Significant difference is also seen between the group DAPT and CRT, DAPRT and CT $(\mathrm{p}=0.045)$, DAPRT and DAMT $(\mathrm{p}=0.04)$. DAPT and DAPRT show highly significant difference when compared with other types. Moreover, in the buccolingual dimension, Dual-arch plastic tray with Tray material was the only group showing negative deviation of certain (4 of the 15 samples) gypsum dies, indicating that these dies were smaller than implant abutment. A possible explanation for these negative values could be the effect of tray adhesive and the flexure of plastic tray acting together. No significant difference between the three tray types when Rigid Tray material was used also indicates that rigidity of impression material may help in reducing the effects of tray flexure in dual arch impression. This is in accordance with study by Ceyhan et al ${ }^{[18]}$ and Kulkarni PR et al ${ }^{[19]}$ where statistically significant differences were found in buccolingual and occlusogingival dimensions with viscosity selection of impression material
Table 3 displays the mean mesiodistal measurement of the implant abutments $(3.440 \mathrm{~mm} \pm 0.419 \mathrm{~mm})$ and of the gypsum dies, obtained from the 6 impression types. The standard deviation associated with the working dies ranged between $0.416 \mathrm{~mm}$ and $0.424 \mathrm{~mm}$ ). The mean mesiodistal dimensional difference of all 6 impression types has a negative value indicating that the gypsum dies were smaller than the corresponding implant abutment in the mesiodistal dimension. Table 4 displays the mean occlusogingival measurement of the implant abutments $(4.546 \mathrm{~mm} \pm 0.390 \mathrm{~mm})$ and the mean occlusogingival measurement of the gypsum dies obtained from the 6 impression types. The standard deviation associated with the working dies ranged between $0.384 \mathrm{~mm}$ and $0.406 \mathrm{~mm})$. The mean occlusogingival dimensional difference of all the 6 impression types was negative indicating shorter gypsum dies than the corresponding implant abutment in the occlusogingival dimension. DAMRT gave dies that deviated the least $(0.0085 \mathrm{~mm})$ from the implant abutment and the result was very highly significant $(p<0.001)$.

Table 5 displays the results of the post hoc tests (Tukey's) conducted for the occlusogingival dimension. A highly significant mean difference between DAMRT and CT $(\mathrm{p}=$ 0.003), DAMRT and CRT $(\mathrm{p}=0.036)$, DAMRT and DAPT $(p<0.001)$, DAMRT and DAPRT $(\mathrm{p}=0.001)$, DAMRT and DAMT $(\mathrm{p}=0.001)$ was seen. For a single arch tray, the shrinkage of impression material towards the tray walls occurs in both the occlusogingival and buccolingual direction. With a dual-arch tray, only the buccolingual direction would be affected if the tray was rigid, as there is only a paper insert separating the tray into upper and lower halves, in the occlusogingival direction ${ }^{[17]}$. This possibly explains the significant difference $(p<0.001)$ seen between DAMRT and all other impression types. The DAMRT also produced dies that were shorter in occlusogingival dimension than the implant abutment, but deviated the least $(8.5 \mu \mathrm{m})$ when compared to other impression types (which ranged from $18.7 \mu \mathrm{m}$ to $28.9 \mu \mathrm{m})$. This is in agreement with study by Santayana de Lima LM et al ${ }^{[20]}$, and Ceyhan et al ${ }^{[18]}$ where metal dual arch trays produced dies with least amount of distortion. Another possible explanation for the shorter occlusogingival dimension might be pouring of the counter impression first. The weight of the stone might cause shorter dies in the occlusogingival dimension on the working side. ${ }^{29}$ Graph 1 gives a graphical analysis of the deviation of gypsum dies from the corresponding implant abutment in all three dimensions for all impression types. The deviation which ranges between $-0.03 \mathrm{~mm}$ and $+0.02 \mathrm{~mm}$ is well within clinical standards to make clinically successful impressions of single tooth implant abutment.

Table 6 displays the mean score for each impression type. CT and CRT have a mean score of 4.8 and 5.1 respectively, whereas DAPT, DAMT, DAPRT, DAMRT have scores of $2.6,3.13,2.7$ and 3.5 respectively. The results were very highly significant $(p<0.001)$.

Table 7 displays the results of the post hoc tests (MannWhitney U test) for comfort level. CT and CRT groups are shown to have highly significant difference when compared to the rest of the four impression type groups ie. DAPT, DAPRT, DAMT and DAMRT (p ranged between 0.002 and $<0.001)$. On the other hand, there is no significant difference seen between CT and CRT or between DAPT, DAPRT, DAMT and DAMRT indicating that subjects showed preference for the dual-arch impressions compared to Conventional full arch impressions, without significant 
difference between the plastic and metal trays or impression materials

The measurements made on the stone casts are potentially affected not only by the impression material and the tray type but also by the expansion of the dental stone used. In this investigation the die stone with a setting expansion of $0.1 \%$ was International dental standards states that $0.15 \%$ is the maximum linear dimensional change of elastomeric impression materials. The observed expansion of type IV stone is $0.08 \%$ to $0.1 \%$, may compensate for any dimensional change in the polymerized impression material ${ }^{[14]}$. Also the coefficient of thermal expansion of implant abutment may have influenced its dimensions when measured intraorally versus dimensions assessed extra orally. This effect may have been minimized by air drying the abutment for 5 seconds before each impression as done in this study. Another possible source of distortion could be the impression material pulling away from the adhesive in certain areas of the complete arch trays. No evidence of this was seen during the study, however, these trays were the most difficult to remove and considerable force was required in certain situations in excess of bond strength of the adhesives used. This is probably one of the reasons why complete arch custom tray impression tray was rated as the most uncomfortable of the different types used.

\subsection{Tables and Graphs}

Table 1: Results of One-way ANOVA for the buccolingual dimension:

\begin{tabular}{|c|c|c|c|c|c|}
\hline & $\mathbf{N}$ & $\begin{array}{l}\text { Mean dimension in mm. } \\
\text { (SD) }\end{array}$ & $\begin{array}{l}\text { Mean buccolingual dimensional difference of gypsum } \\
\text { die from implant abutment in mm. (SD) }\end{array}$ & F value & p value \\
\hline Implant abutment & 15 & $3.399(0.345)$ & & & \\
\hline CT & 15 & $3.415(0.344)$ & $1.61 \mathrm{E}-02(9.5309 \mathrm{E}-03)$ & & \multirow{6}{*}{$0.001 *$} \\
\hline CRT & 15 & $3.414(0.344)$ & $1.43 \mathrm{E}-02$ (7.7797E-03) & & \\
\hline DAPT & 15 & $3.406(0.343)$ & $6.20 \mathrm{E}-03(6.9611 \mathrm{E}-03)$ & & \\
\hline DAPRT & 15 & $3.407(0.344)$ & 4.879 & & \\
\hline DAMT & 15 & $3.416(0.345)$ & $1.63 \mathrm{E}-02(7.6108 \mathrm{E}-03)$ & & \\
\hline DAMRT & 15 & $3.412(0.343)$ & $1.29 \mathrm{E}-02(6.1396 \mathrm{E}-03)$ & & \\
\hline
\end{tabular}

$\mathrm{F}=$ One-way ANOVA; $\mathrm{aE}-0 \mathrm{~b}=\mathrm{a} \times 10^{-\mathrm{b}} *$ The mean difference is significant at the 0.05 level

Table 2: Post hoc test Tukey HSD: Multiple comparisons of the buccolingual dimension

\begin{tabular}{|c|c|c|c|c|}
\hline Dependent variable & (l) Impression Type & (J) Impression type & Mean difference $(\mathrm{I}$ - J) & p value \\
\hline \multirow{30}{*}{$\begin{array}{l}\text { Buccolingual dimensional difference from implant abutment } \\
\text { in } \mathrm{mm} \text {. }\end{array}$} & \multirow{5}{*}{ CT } & CRT & $1.8000 \mathrm{E}-03$ & 0.985 \\
\hline & & DAPT & $9.9333 \mathrm{E}-03 *$ & 0.006 \\
\hline & & DAPRT & $8.0000 \mathrm{E}-03 *$ & 0.045 \\
\hline & & DAMT & $-1.333 \mathrm{E}-04$ & 1.000 \\
\hline & & DAMRT & $3.2667 \mathrm{E}-03$ & 0.833 \\
\hline & \multirow{5}{*}{ CRT } & CT & $-1.800 \mathrm{E}-03$ & 0.985 \\
\hline & & DAPT & $8.1333 \mathrm{E}-03 *$ & 0.040 \\
\hline & & DAPRT & $6.2000 \mathrm{E}-03$ & 0.210 \\
\hline & & DAMT & $-1.933 \mathrm{E}-03$ & 0.980 \\
\hline & & DAMRT & $1.466 \mathrm{E}-037$ & 0.994 \\
\hline & \multirow{5}{*}{ DAPT } & CT & $-9.933 \mathrm{E}-03 *$ & 0.006 \\
\hline & & CRT & $-8.133 \mathrm{E}-03 *$ & 0.040 \\
\hline & & DAPRT & $-1.933 \mathrm{E}-03$ & 0.980 \\
\hline & & DAMT & $-1.007 \mathrm{E}-02 *$ & 0.005 \\
\hline & & DAMRT & $-6.667 \mathrm{E}-03$ & 0.148 \\
\hline & \multirow{5}{*}{ DAPRT } & CT & $-8.000 \mathrm{E}-03 *$ & 0.045 \\
\hline & & CRT & $-6.200 \mathrm{E}-03$ & 0.210 \\
\hline & & DAPT & $1.9333 \mathrm{E}-03$ & 0.980 \\
\hline & & DAMT & $-8.133 \mathrm{E}-03^{*}$ & 0.040 \\
\hline & & DAMRT & $-4.733 \mathrm{E}-03$ & 0.505 \\
\hline & \multirow{5}{*}{ DAMT } & CT & 1.3333E-04 & 1.000 \\
\hline & & CRT & $1.9333 \mathrm{E}-03$ & 0.980 \\
\hline & & DAPT & $1.0067 \mathrm{E}-02 *$ & 0.005 \\
\hline & & DAPRT & $8.1333 \mathrm{E}-03^{*}$ & 0.040 \\
\hline & & DAMRT & $3.4000 \mathrm{E}-03$ & 0.808 \\
\hline & \multirow{5}{*}{ DAMRT } & CT & $-3.267 \mathrm{E}-03$ & 0.833 \\
\hline & & CRT & $-1.467 \mathrm{E}-03$ & 0.994 \\
\hline & & DAPT & $6.6667 \mathrm{E}-03$ & 0.148 \\
\hline & & DAPRT & $4.7333 \mathrm{E}-03$ & 0.505 \\
\hline & & DAMT & $-3.400 \mathrm{E}-03$ & 0.808 \\
\hline
\end{tabular}

*. The mean difference is significant at the 0.05 level, $\mathrm{aE}-0 \mathrm{~b}=\mathrm{a} \times 10^{-\mathrm{b}}$

Table 3: Results of One-way ANOVA for the mesiodistal dimension

\begin{tabular}{|c|c|c|c|c|c|}
\hline & $\mathbf{N}$ & Mean dimension in $\mathrm{mm}$. (SD) & $\begin{array}{l}\text { Mean mesiodistal dimensional difference of working die } \\
\text { from implant abutment in } \mathrm{mm} \text {. (SD) }\end{array}$ & F value & $p$ value \\
\hline Implant abutment & 15 & $3.440(0.419)$ & & & \\
\hline CT & 15 & $3.425(0.417)$ & $-1.50 \mathrm{E}-02(6.7718 \mathrm{E}-03)$ & \multirow{6}{*}{1.953} & \multirow{6}{*}{0.094} \\
\hline CRT & 15 & $3.423(0.420)$ & $-1.63 \mathrm{E}-02(1.4114 \mathrm{E}-02)$ & & \\
\hline DAPT & 15 & $3.427(0.424)$ & $-1.27 \mathrm{E}-02(1.3823 \mathrm{E}-02)$ & & \\
\hline DAPRT & 15 & $3.433(0.418)$ & $-6.93 \mathrm{E}-03(3.6148 \mathrm{E}-03)$ & & \\
\hline DAMT & 15 & $3.424(0.417)$ & $-1.55 \mathrm{E}-02(6.1513 \mathrm{E}-03)$ & & \\
\hline DAMRT & 15 & $3.429(0.416)$ & $-1.08 \mathrm{E}-02(9.3747 \mathrm{E}-03)$ & & \\
\hline
\end{tabular}

$\mathrm{F}=$ One-way ANOVA; $\mathrm{aE}-0 \mathrm{~b}=\mathrm{a} \times 10^{-\mathrm{b}} *$. The mean difference is significant at the 0.05 level 
Table 4: Results of One-way ANOVA for the occlusogingival dimension

\begin{tabular}{|c|c|c|c|c|}
\hline & $\mathbf{N}$ & $\begin{array}{c}\text { Mean dimension in } \\
\mathbf{m m} \text {. (SD) }\end{array}$ & $\begin{array}{c}\text { Mean Occlusogingival Dimensional difference of working die } \\
\text { from implant abutment in mm. (SD) }\end{array}$ & F value \\
\hline Implant abutment & 15 & $4.546(0.390)$ & & \\
\hline CT & 15 & $4.524(0.387)$ & $-2.15 \mathrm{E}-02(1.0070 \mathrm{E}-02)$ & \\
\hline CRT & 15 & $4.527(0.388)$ & $-1.87 \mathrm{E}-02(9.5578 \mathrm{E}-03)$ & \multirow{2}{*}{8.056} \\
\hline DAPT & 15 & $4.517(0.384)$ & $-2.89 \mathrm{E}-02(1.0687 \mathrm{E}-02)$ & $<0.001 *$ \\
\hline DAPRT & 15 & $4.557(0.406)$ & $-2.22 \mathrm{E}-02(1.0213 \mathrm{E}-02)$ & \\
\hline DAMT & 15 & $4.523(0.392)$ & $-2.29 \mathrm{E}-02(9.0196 \mathrm{E}-03)$ & \\
\hline DAMRT & 15 & $4.537(0.389)$ & $-8.53 \mathrm{E}-03(3.9073 \mathrm{E}-03)$ & \\
\hline
\end{tabular}

$\mathrm{F}=$ One-way ANOVA $\mathrm{aE}-0 \mathrm{~b}=\mathrm{a} \times 10^{-\mathrm{b}} *$. The mean difference is significant at the 0.05 level

Table 5: Post hoc test Tukey HSD: Multiple comparisons of the occlusogingival dimension

\begin{tabular}{|c|c|c|c|c|}
\hline Dependent variable & $\begin{array}{c}\text { (l) Impression } \\
\text { Type }\end{array}$ & (J) Impression type & $\begin{array}{c}\text { Mean difference } \\
(\mathbf{I}-\mathrm{J})\end{array}$ & $p$ value \\
\hline \multirow{30}{*}{$\begin{array}{c}\text { Occlusogingival } \\
\text { dimensional difference from implant abutment in } \mathrm{mm} \text {. }\end{array}$} & \multirow{5}{*}{$\mathrm{CT}$} & CRT & $-2.800 \mathrm{E}-03$ & 0.960 \\
\hline & & DAPT & 7.4000E-03 & 0.248 \\
\hline & & DAPRT & 6.6667E-04 & 1.000 \\
\hline & & DAMT & $1.4000 \mathrm{E}-03$ & 0.998 \\
\hline & & DAMRT & $-1.300 \mathrm{E}-02^{*}$ & 0.003 \\
\hline & \multirow{5}{*}{ CRT } & CT & $2.8000 \mathrm{E}-03$ & 0.960 \\
\hline & & DAPT & $1.0200 \mathrm{E}-02 *$ & 0.036 \\
\hline & & DAPRT & $3.4667 \mathrm{E}-03$ & 0.906 \\
\hline & & DAMT & 4.2000E-03 & 0.811 \\
\hline & & DAMRT & $-1.020 \mathrm{E}-02 *$ & 0.036 \\
\hline & \multirow{5}{*}{ DAPT } & $\mathrm{CT}$ & $-7.400 \mathrm{E}-03$ & 0.248 \\
\hline & & CRT & $-1.020 \mathrm{E}-02 *$ & 0.036 \\
\hline & & DAPRT & $-6.733 \mathrm{E}-03$ & 0.349 \\
\hline & & DAMT & $-6.000 \mathrm{E}-03$ & 0.480 \\
\hline & & DAMRT & $-2.040 \mathrm{E}-02 *$ & $<0.001$ \\
\hline & \multirow{5}{*}{ DAPRT } & $\mathrm{CT}$ & $-6.667 \mathrm{E}-04$ & 1.000 \\
\hline & & CRT & $-3.467 \mathrm{E}-03$ & 0.906 \\
\hline & & DAPT & $6.7333 \mathrm{E}-03$ & 0.349 \\
\hline & & DAMT & 7.3333E-04 & 1.000 \\
\hline & & DAMRT & $-1.367 \mathrm{E}-02 *$ & 0.001 \\
\hline & \multirow{5}{*}{ DAMT } & $\mathrm{CT}$ & $-1.400 \mathrm{E}-03$ & 0.998 \\
\hline & & CRT & $-4.200 \mathrm{E}-03$ & 0.811 \\
\hline & & DAPT & $6.0000 \mathrm{E}-03$ & 0.480 \\
\hline & & DAPRT & $-7.333 \mathrm{E}-04$ & 1.000 \\
\hline & & DAMRT & $-1.440 \mathrm{E}-02 *$ & 0.001 \\
\hline & \multirow{5}{*}{ DAMRT } & $\mathrm{CT}$ & $1.3000 \mathrm{E}-02^{*}$ & 0.003 \\
\hline & & CRT & $1.0200 \mathrm{E}-02 *$ & 0.036 \\
\hline & & DAPT & $2.0400 \mathrm{E}-02 *$ & $<0.001$ \\
\hline & & DAPRT & $1.3667 \mathrm{E}-02^{*}$ & 0.001 \\
\hline & & DAMT & $1.4400 \mathrm{E}-02 *$ & 0.001 \\
\hline
\end{tabular}

*. The mean difference is significant at the 0.05 level $\mathrm{aE}-0 \mathrm{~b}=\mathrm{a} \times 10^{-\mathrm{b}}$

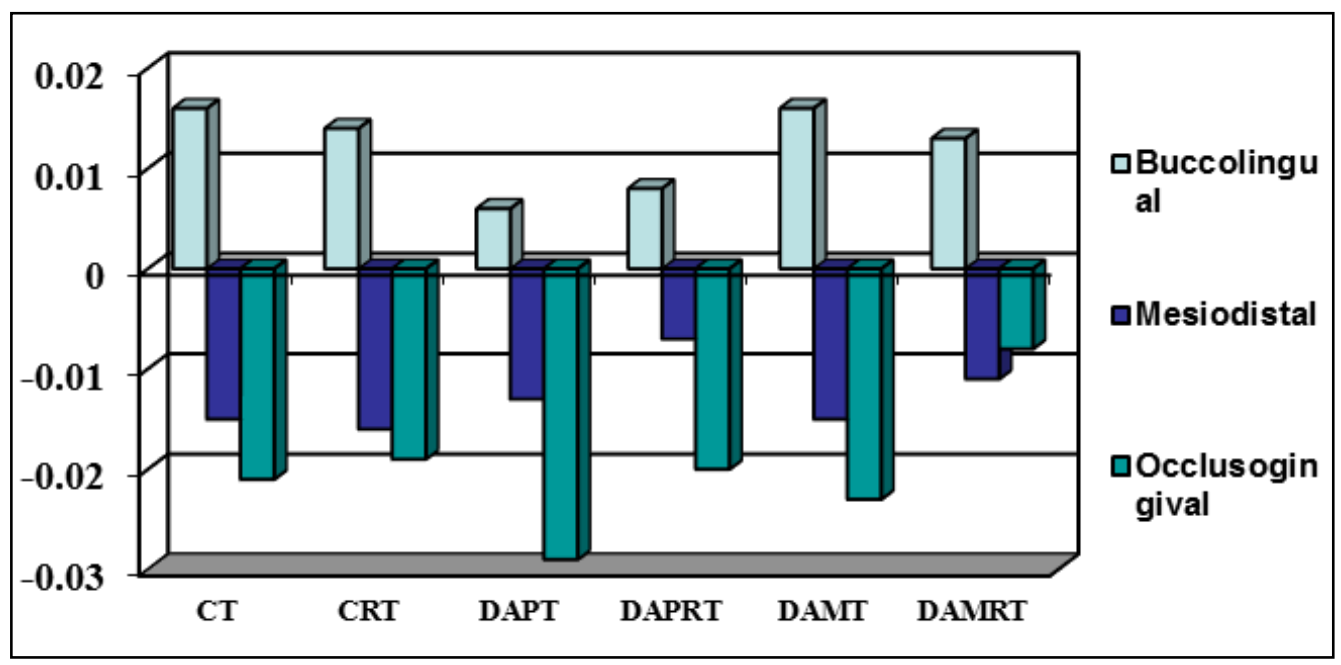

Graph 1: Mean buccolingual, mesiodistal and occlusogingival dimensional difference ( $\mathrm{mm}$ ) of working dies from the implant abutment for the 6 impression types. 
Table 6: Results of Kruskal-Wallis test for comfort level scores.

\begin{tabular}{|c|c|c|c|c|}
\hline Impression type & $\mathbf{N}$ & Mean score (SD) & Kruskal-Wallis Test statistic & p value \\
\hline CT & 15 & $4.8000(1.61245)$ & & \\
\hline CRT & 15 & $5.1333(1.35576)$ & & \\
\hline DAPT & 15 & $2.6000(1.29835)$ & & \multirow{2}{*}{34.074} \\
\hline DAPRT & 15 & $2.7333(1.38701)$ & & \\
\hline DAMT & 15 & $3.1333(1.12546)$ & & \\
\hline DAMRT) & 15 & $3.5000(1.71739)$ & & \\
\hline
\end{tabular}

*. The mean score is significant at the 0.05 level

Table 7: Post hoc test Mann -Whitney U test: multiple comparisons for comfort levels

\begin{tabular}{|c|c|c|}
\hline Impression type & Z value & p value \\
\hline CT vs CRT & -0.974 & 0.330 \\
DAPT & -3.498 & $<0.001 \mathrm{VHS}^{*}$ \\
DAPRT & -3.169 & $0.002 \mathrm{HS}^{\#}$ \\
DAMT & -3.264 & $0.001 \mathrm{VHS}^{*}$ \\
DAMRT & -3.371 & $0.001 \mathrm{VHS}^{*}$ \\
\hline CRT vs DAPT & -3.845 & $<0.001 \mathrm{VHS}^{*}$ \\
DAPRT & -3.540 & $<0.001 \mathrm{VHS}^{*}$ \\
DAMT & -3.621 & $<0.001 \mathrm{VHS}^{*}$ \\
DAMRT & -3.646 & $<0.001 \mathrm{VHS}^{*}$ \\
\hline DAMT & -0.170 & 0.865 \\
DAMRT & -0.128 & 0.898 \\
\hline DAPT vs DAPRT & -1.196 & 0.232 \\
\hline DAMRT vs DAMT & -0.298 & 0.765 \\
\hline DAMT vs DAMRT & -1.070 & 0.285 \\
\hline DAPRT & -1.280 & 0.201 \\
\hline
\end{tabular}

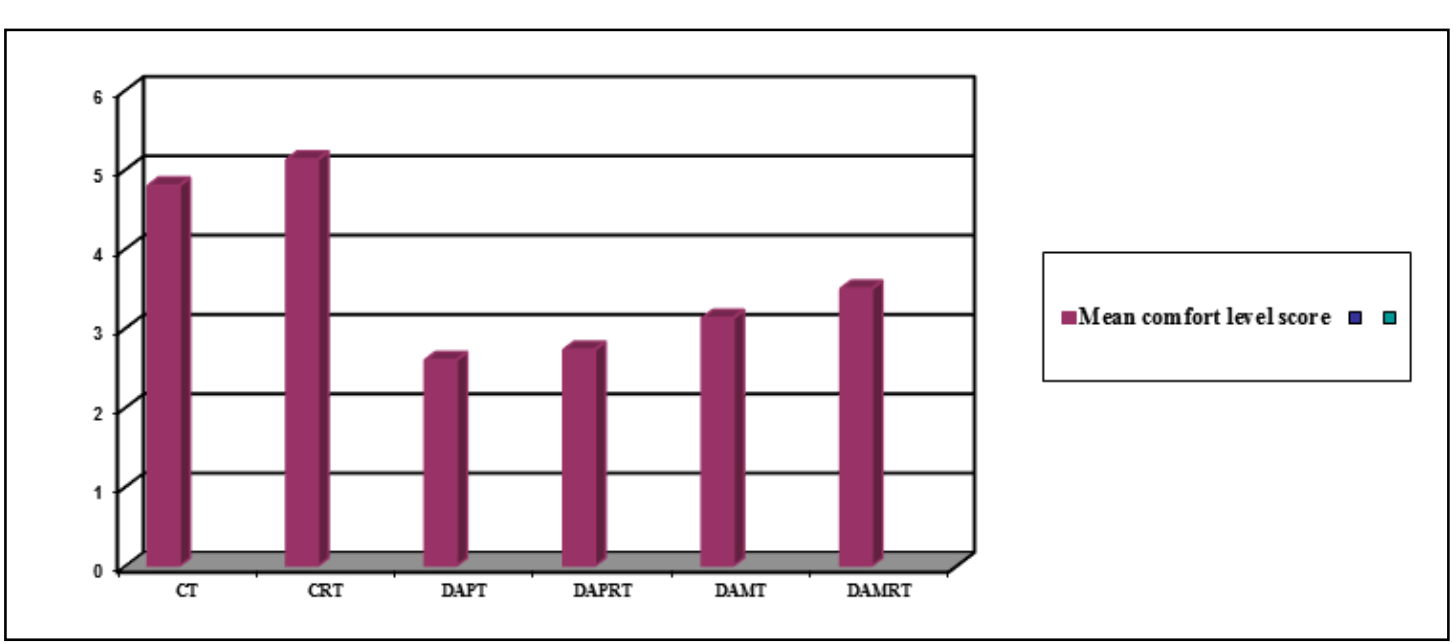

Graph 2: Mean comfort level scores for the 6 impression types on a scale of 1 to 6

\section{Conclusion}

Within the limitations of this study, the following conclusions were drawn:

1. Though all impression types studied produced gypsum dies that deviated from the corresponding implant abutment, they were within clinical standards to make clinically successful impressions of single tooth implant abutment.

2. Rigid Tray impression material used with metal and plastic dual arch trays produced gypsum dies that were closest in dimensions to the implant abutment.

3. Dual-arch tray technique was found to be more comfortable than the Conventional complete arch custom tray technique.

With significant saving in time and material, Dual arch impression technique can be used as an accurate method in restoration of single teeth. It can be put to use successfully, as long as the operator understands the indications and contraindications of the procedure. Apart from the 3 dimensions considered in this study, other parameters like inter abutment dimensions, occlusal relationships and marginal fit, that dictate the accuracy of the model and the success of indirect restorations, in more demanding restorative procedures, need further investigation.

\section{References}

1. Cox JR.A clinical study comparing marginal and occlusal accuracy of crowns fabricated from dual arch and complete arch impressions. Aust Dent J. 2005; 50:90-4.

2. Cox JR, Brandt RL, Hughes HJ. Double arch impression technique. A solution to prevent supra occlusion in the indirect restoration. Gen Dent. 2000; 48:86-91.

3. Wilson EG, Werrin SR. Double arch impressions for simplified restorative dentistry. J Prosthet Dent. 1983; 49:198-202

4. Brazilay I, Myers ML. The dual-arch impression. Quintessence Int. 1987; 18:293-95. 
5. Parker MH, Cameron SM, Hughbanks JC, Reid De. Comparision of occlusal contacts in maximum intercuspation for two impression techniques. J Prosthet Dent. 1997; 78:255-9.

6. Muller J, Horz W, Kraft E. An Experimental study on the influence of derived casts on the accuracy of different recording materials. Part 1: Plaster, impression compound and wax. J Prosthet Dent. 1990; 63:263-69.

7. Tripodakis AP, Vergos VK, Tsoutsos AG. Evaluation of the accuracy interocclusal records in relation to two recording techniques. J Prosthet Dent. 1997; 77:141-46

8. Burke FJT, Crisp RJ. A practice-based assessment of the handling of a fast-setting polyvinyl siloxane impression material used with the dual arch technique. Quintessence Int. 2001; 32:805-10.

9. Lane DA, Randall RC, Lane NS, Wilson NHF. A clinical trial to compare double arch and complete arch impression techniques in the provision of indirect restorations. J Prosthet Dent. 2003; 89:141-5.

10. Ceyhan JA, Johnson GH, Lepe X, Phillips KM. A clinical study comparing the three-dimensional accuracy of a working die generated from two dual arch trays and a complete arch tray. J Prosthet Dent. 2003; 90:228-34.

11. Boulton JL, Gage JP, Vincent PF, Basford KE. A laboratory study of dimensional changes for three elastomeric materials using custom and stock trays. Aust Dent J. 1996; 41:398-404.

12. DeMarco TJ, Paine S. Mandibular dimensional change. J Prosthet Dent. 1974; 31:482-5

13. Douglass GD. The cast restoration - Why is it high? J Prosthet Dent. 1975; 34:491-5.

14. Cox JR, Brandt RL, Hughes HJ. A clinical pilot study of the dimensional accuracy of double-arch and complete arch impressions. J Prosthet Dent. 2002; 87:510-15.

15. Hoos JC, Kaplowitz GJ. Proper placement of dual arch impression trays. J Am Dent Assoc. 2003; 134:729-30.

16. Johnson GH, Craig RG. Accuracy of four types of rubber impression materials compared with time of pour and a repeat pour of models. J Prosthet Dent. 1985; 53:484-90.

17. Breeding LC, Dixon DL. Accuracy of casts generated from dual arch impressions. J Prosthet Dent. 2000; 84:403-7.

18. Ceyhan JA, Johnson GH, Lepe X. The effect of tray selection, viscosity of impression material, and sequence of pour on the accuracy of dies made from dual arch impressions. J Prosthet Dent. 2003; 90:143-9.

19. Kulkarni PR, Kulkarni RS, Shah RJ, Chhajlani R, Saklecha B, Maru KA. Comparative Evaluation of Accuracy of the Dies Affected by Tray Type, Material Viscosity, and Pouring Sequence of Dual and Single Arch ImpressionsAn In vitro Study. J Clin Diagn Res. 2017; 11(4):128-135.

20. Santayana de Lima LM, Borges GA, Burnett LH Jr, Spohr AM. In vivo study of the accuracy of dual-arch impressions. J Int Oral Health. 2014; 6(3):50-5. 